\title{
Low reproductive success of black skimmers associated with low food availability
}

Christopher A. Gordon

Daniel A. Cristol

College of William and Mary, dacris@wm.edu

Ruth A. Beck

Follow this and additional works at: https://scholarworks.wm.edu/aspubs

Part of the Behavior and Ethology Commons

\section{Recommended Citation}

Gordon, Christopher A.; Cristol, Daniel A.; and Beck, Ruth A., Low reproductive success of black skimmers associated with low food availability (2000). Waterbirds, 23, 468-474.

https://scholarworks.wm.edu/aspubs/619

This Article is brought to you for free and open access by the Arts and Sciences at W\&M ScholarWorks. It has been accepted for inclusion in Arts \& Sciences Articles by an authorized administrator of W\&M ScholarWorks. For more information, please contact scholarworks@wm.edu. 


\title{
Low Reproductive Success of Black Skimmers Associated with Low Food Availability
}

\author{
Christopher A. Gordon, Daniel A. Cristol ${ }^{1}$ And Ruth A. Beck \\ Department of Biology, College of William and Mary, Williamsburg, VA 23187, USA \\ ${ }^{1}$ Internet:dacris@wm.edu
}

\begin{abstract}
Black Skimmers (Rynchops niger) have undergone an extended population decline over much of their range, including the coast of Virginia, USA, where the population has decreased by $80 \%$ in the last two decades. A combination of starvation, flooding, predation and human disturbance has been cited as the cause of low reproductive success. This study tested the hypothesis that, at a colony on an artificial island in the James River, Hampton County, VA, a shortage of food was responsible for the chronically low success of breeding skimmers at a site protected from flooding, predation or human disturbance. Parents that fed more fledged a higher proportion of nestlings, suggesting a relationship between food and chick survival. Abundance of one of the two primary prey species underwent a regional decline during the skimmer breeding season, and both primary prey species began seasonal declines before most skimmer chicks had fledged. Both of these fish species have also undergone long-term declines in the region and their annual abundance has been closely correlated with regional skimmer numbers. Mortality of eggs was low (30\%) while mortality of chicks was high (70\%), and nestling growth rate and size at fledging appeared to be lower at this site than published data would indicate was the case at other sites, all consistent with the hypothesis that starvation was occurring. Finally, first-hatched chicks were more likely to survive than were their siblings, consistent with starvation as a primary cause of death. Received 13 September 1999, resubmitted 21 January 2000 , accepted 21 January 2000
\end{abstract}

Key words.-Black Skimmer, feeding rate, food availability, growth rate, reproductive success, Rynchops niger.

Waterbirds 23(3): 468-474, 2000

The number of Black Skimmer (Rynchops niger) colonies in North America has dropped precipitously in the last century (Burger and Gochfeld 1990). On the Eastern Shore of Virginia (lower Delmarva Peninsula), the Black Skimmer population has declined from a high of $>10,000$ adults in 1977 to $<2,000$ in 1998 (Williams et al. 1998). Numerous studies have measured skimmer nesting success in North America (Tables 1 and 2), often reporting poor reproduction due to predation, human disturbance, rainstorms, tidal flooding and starvation (Smith 1982; Keller 1992; O’Connell 1992; Mathews 1995). The objective of this study was to determine whether skimmer reproductive success at a colony protected from predation, human disturbance and flooding was limited by food availability.

Extensive monitoring of skimmer hatching and fledging success at this colony over several years indicates that reproductive success has generally been low, despite ostensibly favorable conditions (Keller 1992; Mathews 1995, Table 2). This study site is ideal for testing the hypothesis that skimmer reproduction may be limited by food avail- ability because most other putative causes of low reproductive success were absent due to management of the colony (see below). We hypothesized that if foraging grounds were distant, or fish scarce, then adults might not be able to adequately provision young. Our specific predictions were that if skimmer reproduction were food-limited at this site, we would find (1) a correlation between feeding rate and fledging success at individual nests, (2) evidence of relatively low availability of the primary prey species during the pre-fledging period when chicks were being fed, (3) high chick mortality relative to egg mortality, and (4) slow nestling growth rates, fledgling weights and fledging rates relative to data from other skimmer colonies. Since others have reported starvation as a function of hatch order in this and many other bird species (i.e., older nestlings out-compete siblings for food, Depue 1974; Erwin 1977), we also predicted that (5) first-hatched nestlings would have higher fledging rates. While starvation has been reported before as a cause of nestling mortality in Black Skimmers (e.g., Burger and Gochfeld 1990; Taylor 1997), the present study is the first to exam- 
Table 1. Black Skimmer breeding success; East and Gulf Coast, USA.

\begin{tabular}{lcccccl}
\hline \hline State & \# Nests & \# Eggs & \% Hatch & \% Fledge & \# Chicks & \multicolumn{1}{c}{ Reference } \\
\hline NJ & - & - & - & - & 0.75 & Burger and Gochfeld 1990 \\
NJ & - & 2.9 & 0.43 & - & 0.50 & Burger and Gochfeld 1990 \\
NY & 190 & 3.70 & 0.88 & - & - & Safina and Burger 1983 \\
NY & - & - & - & - & 0.65 & Burger and Gochfeld 1990 \\
SC & 57 & 3.8 & 0.35 & 0.95 & 1.2 & Blus and Stafford 1980 \\
TX & 94 & 3.44 & 0.63 & 0.53 & 0.87 & Custer and Mitchell 1987 \\
TX & 105 & 3.3 & 0.60 & 0.46 & 0.67 & King et al. 1991 \\
TX & 345 & 3.14 & 0.57 & 0.54 & 1.30 & King and Krynitsky 1986 \\
TX & 477 & 3.3 & 0.45 & - & 1.0 & White et al. 1984 \\
TX & 353 & 3.18 & 0.56 & 0.34 & 0.62 & Depue 1974 \\
VA & 110 & 3.55 & 0.79 & 0.11 & 0.38 & Erwin 1977 \\
VA, MD & 118 & 3.13 & 0.53 & 0.39 & 0.58 & Smith 1982 \\
VA & 180 & 3.04 & - & - & 0.13 & O'Connell 1992 \\
\hline
\end{tabular}

${ }^{1}$ Weighted mean of 13 breeding seasons at 23 sites.

${ }^{2}$ Weighted mean of 14 sites in 1979.

${ }^{3}$ Weighted mean estimated for Ceder Beach, 1976-1979.

ine quantitatively the relationship between food delivery rate and fledging success in Black Skimmers.

METHODS

Study Site

The Hampton Roads Bridge-Tunnel (hereafter, HRBT) spanning the James River in Hampton County, Virginia, USA $\left(36^{\circ} 55^{\prime} \mathrm{N}, 70^{\circ} 30^{\prime} \mathrm{W}\right)$ is the site of a nesting colony of approximately 300 pairs of skimmers, 3,000 pairs of Common Terns (Sterna hirundo) and 50 pairs of Gull-billed Terns (Sterna nilotica). The colony is located on a permanent 10-ha island created in 1972 to support the bridge and a maintenance building. The site is 2.4 $\mathrm{km}$ from the nearest shoreline and $60 \mathrm{~km}$ from the nearest large skimmer colony. The area within sight of the colony is apparently not suitable for skimmer foraging because this was observed only rarely during the course of our study, despite ample opportunity (unpubl. data). The site is managed with nesting birds in mind and is attractive for skimmer nesting because: (1) its elevation minimizes the threat of flooding or washout from storms, (2) mammalian nest predators are completely absent due to inaccessibility and a preventive rat poisoning program, (3) preferred sandy nesting substrate is provided for the skimmers each year by the site manag- ers, (4) herbaceous cover is present to provide shade to mobile hatchlings, and (5) there is negligible human intrusion. Predation by gulls or crows has not been observed at the HRBT, presumably because it is located far from any crow or gull nesting areas.

\section{Monitoring Feeding Rate}

Thirteen plots $(510 \mathrm{~m} \times 10 \mathrm{~m}, 830 \mathrm{~m} \times 2 \mathrm{~m})$, all with bulldozed sand substrate, were established for skimmer nesting in early February 1998 as described by Mathews (1995). The feeding rate (number of fish eaten $\mathrm{h}^{-1}$ nestling $^{-1}$ ) was monitored from 23 June until 1 August, using a combination of day and night observations. Daylight observations were made on 21 days between 23 June and 13 July on nests in seven randomly-selected plots. All nests within a plot were monitored for one hour each day (between 0530 and $2030 \mathrm{~h}$ ), with observation periods chosen to equalize coverage during morning, midday and afternoon, as well as incoming and outgoing tides. Each nest was monitored for 7-14 hours. Night observations were made from 15-21 July on one plot (n $=25$ nests) which was observed continuously during 2100-0300 h under dim artificial light from a nearby construction site. At 14 of these nests both day and night feeding rates were measured. All feeding rate observations were made from a nearby rooftop, using $10 \times$ binoculars and a $15 \times$ spotting scope. We collected uneaten prey during nest checks to determine which fish species were being brought back.

Table 2. Black Skimmer breeding success; Hampton Roads Bridge-Tunnel, Virginia, USA.

\begin{tabular}{rccccl}
\hline \hline \# Nests & \# Eggs & \% Hatch & \% Fledge & \# Chicks & Reference \\
\hline 27 & 3.00 & 0.17 & - & - & Keller 1992 \\
31 & 2.10 & 0.21 & - & - & Keller 1992 \\
350 & 2.44 & 0.23 & 0.15 & 0.09 & Mathews 1995 \\
261 & 2.88 & 0.46 & 0.30 & 0.39 & Mathews 1995 \\
300 & 2.99 & 0.36 & 0.33 & 0.35 & This study, 1997 \\
251 & 2.75 & 0.70 & 0.29 & 0.55 & This study, 1998 \\
\hline
\end{tabular}


Prey Availability Surveys

Seasonal fish abundance data were obtained from two biweekly seine surveys conducted from April through October, 1998 in the creek mouths of the Chesapeake Bay and along the beaches of the Eastern Shore of Virginia by the Virginia Institute of Marine Science (Austin et al. 1998). These surveys collected fish from the water surface to $1.5 \mathrm{~m}$ de th in a transect extending $30 \mathrm{~m}$ from, and perpendicular to, the shoreline. Data are expressed as the log transformed mean number of fish per net haul. The closest sampling site to the skimmer colony was $2.4 \mathrm{~km}$. Long-term regional trends in Atlantic needlefish (Strongylura marina) and menhaden (Brevoortia tyrannus) abundarice were obtained from juvenile striped bass (Morone sxatilis) seine surveys conducted by the Virginia Institute of Marine Science and the Maryland Division of Natural Resources (Austin et al. 1998; Durell 1999, and unpublished long-term data from these surveys available a.t http://www.vims.edu).

\section{Monitoring Reproductive Success}

Ten of the nesting plots described above were enclosed with vinyl-coated poultry wire $(30 \mathrm{~cm}$ high) to constrain the movement of young, thereby allowing determination of their fate (Erwin 1977; Smith 1982). The fate of nests was followed frorn 1 April to 15 September, using a combination of daily cibservations from a nearby rooftop and visits on foot to approximately half the colony every third day. Nests were marked with numbered white survey flags. When young hatched they were given identifying marks, using acrylic nail polish on the down feathers of the lower back. Young were considered fledged if they survived to 91 days, after which they could usually fly out of the enclosures. Young $(\mathrm{N}=128)$ in 64 randomly selected nests were weighed (to one g) every sixth day from 27 June until 12 August to provide growth rate data.

We carried out a preliminary study of hatching and fledging rates using similar methods in 1997. Two unpublished Master's thesis studies employed generally similar monitoring technique:; at the same site. We have provided summary data from these studies in Table 2 for comparative purposes.

\section{Statistical Analysis}

Reproductive success was c.nalyzed using parametric tests when data were normally distributed or approached normality after transformation (ANOVA on the slope of a linear or polynomial regression, logistic regression, or t-test in the case of two sample comparisons); otherwise, non-parametric tests were used as noted. The Mayfield method, an estimator of nest success based on days of nest observation, was used to analyze the probability of survival during incubation and pre-fledging phases of the breeding cycle (Mayfield 1961, 1975). Numbers given after means are standard deviations.

Logistical equations were fitted to growth curves to quantitatively describe growth patterns (Ricklefs 1967, 1968). Linear regression was used to determine the line of best fit among logistic, Gompertz, and von Bertalanffy growth equations (Ricklefs 1967). The growth constant, $\mathrm{K}$, was calculated frorn the slope of the logistic regression line, to compare growth rates between males and females at this site with other published data.

\section{RESULTS}

\section{Effect of Feeding Rate on Fledging Success}

At the sub-sample of nests where both day and night feeding rates were observed, the combined feeding rate was $0.13 \pm 0.17 \mathrm{fish} \mathrm{h}^{-1}$ nestling $^{-1}$. There was a significant positive relationship between a pair's feeding rate and the number of chicks fledged per nest $(\mathrm{N}=$ 14 nests; $\left.\mathrm{R}^{2}=0.49 ; \mathrm{F}_{1,12}=11.54 ; \mathrm{P}<0.01\right)$.

Mean feeding rate at nests monitored during the day was $0.12 \pm 0.10$ fish $^{-1}$ nestling $^{-1}$. Mean feeding rate at nests monitored at night was twice as high $\left(0.25 \pm 0.34\right.$ fish h$^{-1}$ nestling $\left.{ }^{-1}\right)$.

\section{Food Availability}

We collected 268 fish near active skimmer nests. Six species comprised $91 \%$ of the fish collected (Fig. 1). Because Atlantic needlefish and menhaden accounted for $48.5 \%$ and $23.1 \%$ of total individual fish collected, respectively, analyses of prey abundance were restricted to these two species. While collecting uneaten prey probably biased our sample towards larger fish species that young could not swallow as easily, such as needlefish, our analysis probably included many suitable prey items as young skimmers

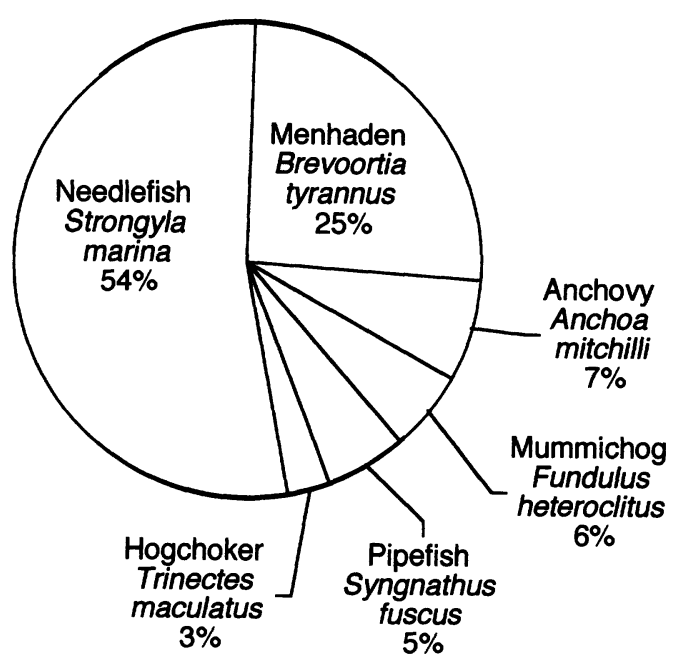

Figure 1. Relative abundance of the top six prey species collected near nests of Black Skimmers at Hampton Roads Bridge-Tunnel, Virginia during the 1998 breeding season. 
will not pick up fish accidentally dropped by parents (Gochfeld and Burger 1994). Our observations of returning adults also suggested a preponderance of needlefish in the diet (unpubl. data).

Needlefish abundance peaked in early July while menhaden abundance peaked in late May (Austin et al. 1998). Both species appeared to decline while most skimmer chicks were still being fed (Fig. 2). Regression of abundance of each of the primary prey species on date indicated that menhaden declined significantly (linear regression: fish $=$ $1.20-0.009 *$ date $\mathrm{R}^{2}=0.50 ; \mathrm{F}_{1,9}=9.12 ; \mathrm{P}<$ $0.01)$ during the breeding season, whereas any apparent change in needlefish abundance was not significant (polynomial regression: fish $=-0.22+0.02 *$ date $0.0001 *$ date $\left.^{2} ; \mathrm{R}^{2}=0.48 ; \mathrm{F}_{2,8}=3.66 ; \mathrm{P}<0.07\right)$.

\section{Fish Abundance and Skimmer Populations}

Since 1975, surveys on the Eastern Shore have monitored the numbers of adult colonial waterbirds each summer, providing a consistent measure that can be used to track trends in population (Williams et al. 1990). The Maryland Department of Natural Resources and the Virginia Institute of Marine Science have monitored long term population trends of fish in the Chesapeake Bay. There was a strong and highly significant relationship between the combined abundance of needlefish and menhaden in the

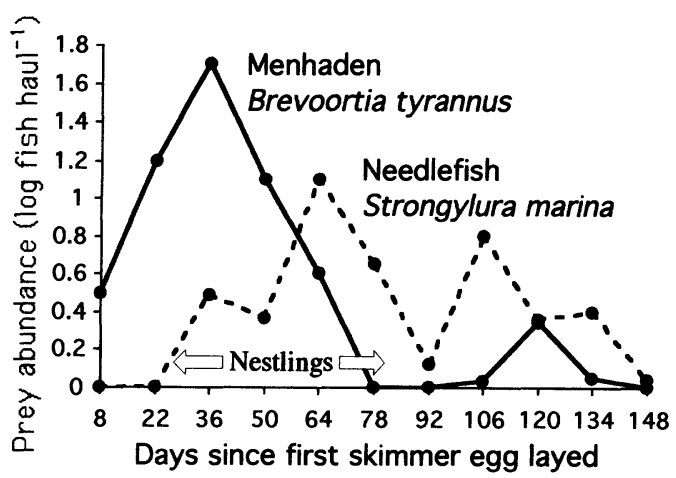

Figure 2. Abundance of menhaden and needlefish in samples throughout the Chesapeake Bay in 1998 shown relative to Black Skimmer breeding cycle at Hampton Roads Bridge-Tunnel, Virginia.
Chesapeake Bay and the adult skimmer populations on the Eastern Shore (linear regression: skimmers $=2866+423 *$ fish; $\mathrm{R}^{2}=0.60$; $\mathrm{F}_{1,22}=32.29 ; \mathrm{P}<0.0001$; Fig. 3).

\section{Reproductive Success}

Clutch size, proportion of eggs hatching, and number of chicks fledged per nest at this site were all significantly lower than the mean for other East and Gulf Coast colonies (Table 3). Mortality was significantly higher during the pre-fledging period than during the incubation period (incubation: 32 nest days with losses, $\mathrm{n}=252$ nests; pre-fledging: 136 nest days with losses, $\mathrm{n}=220$ nests; $\chi_{1}^{2}=$ $112.81 ; \mathrm{P}<0.05)$. This result can be expressed more intuitively; $30 \%$ of 693 eggs failed to hatch while $70 \%$ of 486 chicks failed to fledge. There was no loss of eggs or young from flooding, rainstorms, or tidal surge. There was no evidence of predation on young. Egg predation was absent, except that by migrating Ruddy Turnstones (Arenaria interpres) which were observed eating eggs on seven days in late May, accounting for only $9 \%$ of all hatching failures (19 of 207 failed eggs).

\section{Growth Rates of Young}

Since skimmer young exhibit sexual dimorphism, growth rates of males and females were analyzed separately, using logistic

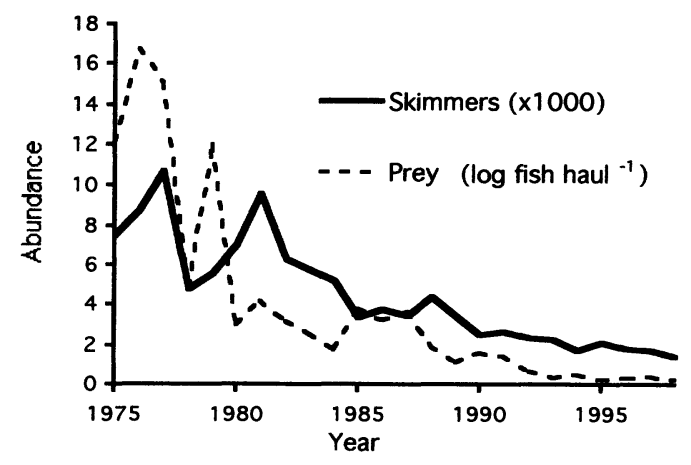

Figure 3. Numbers (in thousands) of adult Black Skimmers counted along Virginia's Eastern Shore during annual surveys since 1975 and combined abundance of menhaden and needlefish sampled in the same years in Virginia and Maryland portions of the Chesapeake Bay (see text for analysis). 
Table 3. Comparison ${ }^{1}$ of Black Skimmer nesting success $(\overline{\mathbf{x}} \pm \mathrm{SD})$ at the Hampton Roads Bridge-Tunnel, Virginia, USA and other East and Gulf Coast, USA sites.

\begin{tabular}{lcccc}
\hline \hline & \# Eggs & \% Hatch & \% Fledge & \# Chicks \\
\hline HRBT & $2.74 \pm 0.36$ & $0.41 \pm 0.20$ & $0.26 \pm 0.01$ & $0.32 \pm 0.19$ \\
East/Gulf & $3.41 \pm 0.26$ & $0.58 \pm 0.16$ & $0.44 \pm 0.26$ & $0.81 \pm 0.36$ \\
Z & 3.26 & 2.00 & 1.89 & 2.12 \\
P & 0.001 & 0.05 & 0.06 & 0.03 \\
\hline
\end{tabular}

${ }^{1}$ Mann-Whitney $\mathrm{U}$ test on weighted means of all data with known sample size from Tables 1 and 2.

growth equations (Ricklefs 1967). Male skimmers fledged at a significantly higher weight $(\mathrm{N}=10 ; \overline{\mathrm{x}}=305 \pm 27.8 \mathrm{~g})$ than did females $\left(\mathrm{N}=12 ; \overline{\mathrm{x}}=243 \pm 15.1 \mathrm{~g} ; \mathrm{t}_{20}=6.65 ; \mathrm{P}\right.$ $<0.0001)$. The logistic growth equations used to plot weight gain through time met the parameters established by Ricklefs for the "line of best fit" when analyzed by linear regression (males: $\mathrm{R}^{2}=0.92 ; \mathrm{F}_{1,9}=122.72 ; \mathrm{P}$ $<0.0001$; females: $\mathrm{R}^{2}=0.907 ; \mathrm{F}_{1,11}=107.46$; $<0.0001)$. The growth constant $K$, calculated separately for each sex, indicated that males had a slightly higher rate of growth $(K=$ $0.20)$ than did females $(K=0.17)$.

\section{Hatch Order and Survival}

Young that hatched earlier within a clutch survived longer than their laterhatched siblings, as indicated by the significant relationship between hatch order and days of survival $\left(\mathrm{R}^{2}=0.44 ; \mathrm{F}_{1,124}=97.26 ; \mathrm{P}<\right.$ 0.0001). Multiple comparisons between number of days survived and hatch order indicated a significant difference between firstand second-, second- and third-, and firstand third-hatched young (mean days survived: first-hatched $=17.1, \mathrm{n}=59$; secondhatched $=10.0, \mathrm{n}=45$; third-hatched $=5.4, \mathrm{n}$ $=22 ; 1>2: \mathrm{P}<0.0001 ; 2>3: \mathrm{P}=0.001 ; 1>3$ : $\mathrm{P}<0.0001)$. Survival to fledging was significantly affected by hatch order (logistic regression: $\log$-likelihood $\chi_{1}^{2}=52.36 ; \mathrm{P}<$ 0.0001 ). Of 37 successful nests, 32 fledged only the first-hatched chick.

\section{Discussion}

As expected for this protected colony, we found no evidence that predation, flooding, or human disturbance affected reproductive success. Despite this, reproductive success was low, as it has been in recent years (Keller 1992; Mathews 1995), compared to colonies in other parts of the East and Gulf Coasts, USA. In general we found support for our hypothesis that skimmer reproduction was being limited by food availability at this site.

We predicted that if food were limited, then variation in parental feeding success should be related to variation in fledging success. Parents that fed young at higher rates fledged more young per nest, supporting our prediction. The feeding rate observed at this site appeared to be lower than feeding rates at other sites. Erwin (1977) reported a feeding rate of 0.43 fish young $^{-1} \mathrm{~h}^{-1}$ for skimmers at a Virginia colony. Burger and Gochfeld (1990, Fig. 8.7) provide data that can be used to estimate a feeding rate of at least 1.5 fish young ${ }^{-1} h^{-1}$ for a New York colony, but suggest that a rate of 0.5-1.0 fish young ${ }^{-1} h^{-1}$ is more typical (M. Gochfeld, pers. comm.). Despite the low rate of delivery at HRBT, this is not unequivocal evidence for food limitation because the biomass per delivery could have been higher at our site.

Reproductive success in birds often declines over the course of the breeding season, sometimes as the result of declines in food availability (e.g., Wiehn and Korpimaki 1997). While we did not perform the experimental food supplementation required to unambiguously demonstrate food-limited reproductive success, we did document a decline in one important prey species over the course of the nesting season. Menhaden, one of the two species most commonly brought back to our study site by skimmers, declined steeply in abundance throughout the Chesapeake Bay. The other important 
prey species, needlefish, peaked in abundance around the time when chicks were hatching, and then showed a negative trend in abundance that was not statistically significant. The fish sampling intervals (14 days) were not close enough together to allow a test of correlation between prey availability and fledging success, but it is clear that there were fewer of the skimmers' two main prey items caught in seine surveys during the time that most chicks were being fed.

Both menhaden and needlefish have experienced approximately $80 \%$ declines in population size since the early 1980's. The number of adult skimmers present on Virginia's Eastern Shore since 1975 has declined by over $80 \%$ (Williams et al. 1990, 1998), and skimmer abundance in any given year was strongly related to the population size of these fish (Fig. 3). While this finding does not address directly the situation at our study site, it is consistent with the idea that skimmer populations are closely tied to the regional abundance of these two fish species.

If reproductive success is food-limited, then most losses should occur after young have hatched and require food from parents. Mortality was higher during the prefledging period than during incubation, consistent with our prediction that parents were unable to provide sufficient food. While not the subject of our original predictions, it is noteworthy that skimmer clutch size at this site was significantly lower than reported for other East Coast sites (Table 3), suggesting the possibility of food shortage during egg-laying as well (Korpimaki and Wiehn 1998).

Slow growth rates of chicks and small size at fledging might be expected if food was severely limited. The average growth rate for the two sexes combined (growth rate constant $\mathrm{K}=0.18$ ) appeared slower than that reported for colonies in Virginia $(\mathrm{K}=0.23$, Erwin 1977) and New Jersey (K=0.28, Gochfeld and Burger 1994). Fledging weights also appeared to be less than reported for these other colonies $(\mathrm{HRBT}=274 \mathrm{~g}$; Virginia $=280$ g, Erwin 1977; New Jersey $=308$ g, Gochfeld and Burger 1994). HRBT skimmers also grew more slowly and fledged lighter than those in a California study (growth rate: 0.28; fledge weight: $318 \mathrm{~g}$, Schew and Collins 1990). Although different methodologies make direct comparisons between these studies difficult, the direction of differences always pointed to a poor pre-fledging environment at our site, consistent with the hypothesis that chicks were food stressed.

Hatch order influences fledging success in skimmers and many other bird species (e.g., Erwin 1977). First-hatched skimmer chicks lived longer and were more likely to fledge than later-hatched chicks, again consistent with the hypothesis that food was limiting survival.

We suggest that adult skimmers were attracted to the colony at the HRBT because it offered suitable substrate for nesting, but then encountered long travel times to find fish, particularly troublesome for skimmers, whose unusual feeding method generally allows them to carry only one fish per trip. During our daytime monitoring of feeding rates, foraging adults usually stayed away for longer than the one-hour observation period (unpubl. data). Skimmers were never observed foraging within sight of the colony, and the primary feeding areas are unknown. One of the sites sampled for fish abundance was only $2.4 \mathrm{~km}$ from the colony. Only 3 of 2594 fish sampled there during the skimmer pre-fledging period were needlefish $(\mathrm{H}$. Austin, unpubl. data), suggesting that this was not an important feeding area. Not only may this colony be far from foraging areas, but the traditionally preferred prey species may now be rare or inaccessible. The two fish genera making up over $90 \%$ of the diet of Virginia skimmers two decades ago (Menidia and Fundulus; Erwin 1977) comprised only $5 \%$ of the fish brought back to this colony. Thus, skimmers at the HRBT are feeding on species that have declined dramatically, and these may not be their historically preferred prey.

Human development will likely continue to displace colonial waterbirds from their natural habitats, thereby making alternative breeding sites such as the artificial island of the HRBT increasingly important. At this site, which would ostensibly seem highly favorable for skimmer breeding, reproductive 
success consistently falls short of colonies at other locations. We conclude that this is due to scarcity of suitable prey within reasonable distance of nests, leading to death of chicks from starvation or exposure. Conservation programs aimed at increasing skimmer populations through creation of new colonies should carefully consider the distance to, and abundance of, suitable prey.

\section{ACKNOWLEDGMENTS}

Herb Austin and Eric Durell generously provided data on fish abundance in Virginia and Maryland, respectively, for which we are extremely grateful. Jason Riddle and Kathy Stephens gave valuable assistance in the field. We are deeply indebted to the Virginia Department of Transportation for allowing us, and the skimmers, to use the HRBT. Arthur-Western Contractors helped by turning the lights on for night observations. The Williamsburg Bird Club provided much-needed financial assistance to CAG. Thanks also to the Virginia Division of Game and Inland Fisheries.

\section{LiTERATURE Gited}

Austin, H. M., A. D. Estes and D. M. Seaver. 1998. Estimation of juvenile striped bass relative abundance in the Virginia portion of Chesapeake Bay. Annual Progress Report. Sportfish Restoration Project F87R4. U.S. Fish and Wildlife Service, Washington, D.C.

Blus, L. J. and C. J. Stafford. 1980. Breeding biology and relation of pollutants to black skimmers and gullbilled terns in South Carolina. Special Scientific Report-Wildlife No. 230. U.S. Fish and Wildlife Service, Washington, D.C.

Burger, J. and M. Gochfeld. 1990. The black skimmer: Social dynamics of a colonial species. Columbia University Press, New York.

Custer, T. W. and C. A. Mitchell. 1987. Organochlorine contaminants and reproductive success of black skimmers in south Texas. Journal of Field Ornithology 58: 480-489.

DePue, J. 1974. Nesting and reproduction of the black skimmer (Rynchops niger niger L.) on four spoil islands in the Laguna Madre, Texas. M.Sc. Thesis. Texas A\&I University, Kingsville, TX.

Durell, E. 1999. Investigation of Striped Bass in the Chesapeake Bay. USFWS Federal Aid Performance Report. Project F-42-11. Maryland Division of Natural Resources, Maryland Fisheries Service, Fisheries Division.

Erwin, R. M. 1977. Black skimmer breeding ecology and behavior. Auk 94: 709-717.

Keller, G. S. 1992. Nesting substrate preference and breeding success of common terns (Sterna hirundo) and black skimmers (Rynchops niger) on the Hampton Roads Bridge-Tunnel. M.A. Thesis. College of William and Mary, Williamsburg, VA.

King, K. A., T. W. Custer and J. S. Quinn. 1991. Effects of mercury, selenium, and organochlorine contaminants on reproduction of Forster's terns and black skimmers nesting in a contaminated Texas bay. Archives of Environmental Contamination and Toxicology 20: 32-40.

King, K. and A. J. Krynitsky. 1986. Population trends, reproductive success, and organochlorine chemical contaminants in waterbirds nesting in Galveston Bay, Texas. Archives of Environmental Contamination and Toxicology 15: 367-376.

Korpimaki, E. and J. Wiehn. 1998. Clutch size in kestrels: Seasonal decline and experimental evidence for food limitation under fluctuating food conditions. Oikos 83:259-272.

Mathews, C. D. 1995. Effects of substrate on hatching success in black skimmers, Rynchops niger, at the Hampton Roads Bridge-Tunnel, Hampton, Virginia. M.A. Thesis. College of William and Mary, Williamsburg, VA.

Mayfield, H. 1961. Nesting success calculated from exposure. Wilson Bulletin 73: 255-262.

Mayfield, H. 1975. Suggestions for calculating nest success. Wilson Bulletin 87: 456-466.

O'Connell, T. J. 1992. The effects of gull predation on the colony reproductive success of terns and skimmers in Virginia. M.A. Thesis. College of William and Mary, Williamsburg, VA.

Ricklefs, R. E. 1967. A graphical method of fitting equations to growth curves. Ecology 48: 978-983.

Ricklefs, R. E. 1968. Patterns of growth in birds. Ibis 110: 419-451.

Safina, C. and J. Burger. 1983. Effects of human disturbance on reproductive success in the black skimmer. Condor 85: 164-171.

Schew, W. A. and C. T. Collins. 1990. Age and sex determination in black skimmer chicks. Journal of Field Ornithology 61: 174-179.

Smith, D.C. 1982. Reproductive success of common tern (Sterna hirundo) and black skimmer (Rynchops niger) in different habitats in Virginia. M.A. Thesis. College of William and Mary, Williamsburg, VA.

Taylor, M. D. 1997. Demography of the black skimmer (Rynchops niger) in Southern California. M.Sc. California State University, Long Beach, CA.

White, D. H., C. A. Mitchell and D. M. Swineford. 1984. Reproductive success of black skimmers in Texas relative to environmental pollutants. Journal of Field Ornithology 55: 18-30.

Wiehn, J. and E. Korpimaki. 1997. Food limitation on brood size: experimental evidence in the Eurasian kestrel. Ecology 78: 2043-2050.

Williams, B., B. Akers, M. Beck, R. Beck and J. Via. 1998. The 1998 colonial and beach nesting waterbird survey of the Virginia barrier islands. Raven 70: 15-19.

Williams, B., R. Beck, B. Akers and J. W. Via. 1990. Longitudinal surveys of beach nesting and colonial waterbirds of the Virginia barrier islands. Virginia Journal of Science 41: 381-388. 